\title{
Perancangan Active Database System pada Sistem Informasi Pelayanan Harga Pasar
}

\author{
Sucipto \\ Sistem Informasi Universitas Nusantara PGRI Kediri \\ Kediri, Indonesia \\ E-mail: sucipto@ unpkediri.ac.id
}

\begin{abstract}
Sistem informasi merupakan sistem yang berkaitan dengan adanya pemrograman dan database. Sebuah sistem informasi yang baik bersifat dinamis. Sistem informasi yang dinamis tidak mungkin terlepas dengan adanya database sebagai tempat penyimpanan data. Pada umumnya database digunakan secara pasif sehingga fungsinya hanya untuk penyimpanan data, padahal database juga dapat sebagai pengendalian sebuah sistem informasi. Beberapa database opensource sudah mendukung untuk pengendalian sistem atau yang dapat disebut juga active database system seperti MySQL, MariaDB dan PosgreSQL. Active database system me mbe rikan fungsi database untuk mendapatkan perilaku reaktif dan me lakukan pengendalian sistem informasi pada tingkat database. Proses bisnis yang biasanya dilakukan oleh bahasa pemrograman sebagai aturan dimasukkan di aplikasi dapat dimasukkan langs ung ke dalam database.penelitian ini dilakukan untuk perancangan active database sistem terhadap pelayanan harga pasar. Pendekatan active database system ini dirancang guna mendapatkan sistem pelayanan aplikatif dan responsif untuk berkolaborasi dengan sistem kendali pada modem.
\end{abstract}

Keywords—active database, sistem informasi, gammu

\section{Pendahuluan}

Database secara umum dapat diartikan sebuah tempat penyimpanan data sebagai pengganti dari sistem konvensional yang berupa dokumen file. Database didefinisikan kumpulan data yang dihubungkan secara bersama-sama, dan gambaran dari data yang dirancang untuk memenuhi kebutuhan informasi dari suatu organisasi [1]. Berbeda dengan sistem file yang menyimpan data secara terpisah, pada database data tersimpan secara terintegrasi.

Pencangan basis data dibuat dalam tiga fase utama, yaitu : (1) Perancangan database konseptual,merupakan proses membangun model dari data yang digunakan dalam sebuah organisasi dan tidak tergantung pada pertimbangan fisik.(2) Perancangan database logical, merupakan proses membangun model dari informasi yang digunakan dalam perusahaan berdasarkan model data spesifikasi, dan terbebas dari DBMS (Database Management systems) tertentu dan pertimbangan fisik lainnya. Hasil akhir dari tahapan ini berupa sebuah kamus data yang berisi semua attribute beserta key- 
nya (primary key, alternate key, dan foreign key) dan entity relational diagram (ERD). (3) Perancangan database fisikal, merupakan proses pembuatan deskripsi dari implementasi database pada penyimpanan sekunder yang menjelaskan relasi dasar, organisasi file, dan indeks yang digunakan untuk mencapai akses yang efesien kedata, dan setiap integraty constraint yang saling berhubungan dan juga pengukuran keamanan (security) [1].

Active Database Management System (ADBMS) pada dasarnya adalah sebuah database konvensional yang sifatnya pasif, dengan kemungkinan untuk berperilaku secara reaktif. Penambahan fungsional reaktif ini ditandai dengan adanya ECA-rules (event-condition-action rules) yang diartikan dengan "jika sebuah event terjadi, cek terhadap kondisi, dan jika bernilai benar, maka sebuah aksi akan dilaksanakan”. Sekali sekelompok aturan-aturan didefinisikan, sebuah Active Database Management System akan melakukan monitoring terhadap event yang terjadi [2].

Beberapa jenis database seperti MySQL, MariaDB dan PosgreSQL memliki kemampuan melakukan active database. Pada penelitian ini menggunakan database MariaDB dikarenakan database ini sudah digunakan pada sistem yang sudah berjalan di sistem informasi staragis pada tempat penelitian. Database MariaDB merupakan turunan dari database MySQL, hampir semua fitur dan syntax yang ada di MySQL terdapat di MariaDB. MySQL sendiri merupakan sebuah perangkat lunak yang digunakan untuk memanajemen basis data baik secara relational maupun objek.

Penelitian ini dilakukan di desa gadungan puncu kabupaten Kediri. Desa ini memiliki pelayanan hargaharga produk pasar mengenai kebutuhan sehari-hari. Peningkatan penyampain sistem harga perlu ditingkatkan dikarenakan informasi pelayanan harga yang sudah berjalan belum terdata secara periodik sehingga proses penyampaian informasi terkendala oleh jarak tempuh dan koneksi internet. Sistem yang berjalan untuk memperoleh informasi dan penyampaian informasi dilakukan di papan pengumuman yang ada di balai desa dan website desa.

Peningkatan sistem informasi dapat dilakukan dengan bantuan teknologi informasi. Penyampaian informasi sebenarnya sudah dilakukan dengan teknologi informasi namun karena dilihat dari wilayah desa sebagian terletak pada area pegunungan. Pada area pengunungan belum terdapat layanan koneksi internet yang memadai dan salah satu teknologi yang dapat digunakan yaitu dengan layanan panggilan telepon maupun pesan singkat ( $s m s$ ). Layanan pesan singkat lebih memudahkan dibandingkan layanan panggilan dikarenakan sifat layanan pesan singkat dapat sewaktu-waktu 24jam sehingga tidak merepotkan perangkat desa bekerja diluar jam kerja yang ditentukan.

Teknologi penggunaan pesan singkat dapat dilakukan dengan SMS Gateway. Penggunaan teknologi ini dapat disinkronkan dengan sistem informasi yang sudah terdapat database pelayanan harga. Kemudahan implementasi sistem pelayanan harga pasar dapat dilakukan dengan perangkat open source 
yaitu gammu. Gammu merupakan sistem yang digunakan untuk pelayanan teknologi SMS Gateway yang terdapat teknologi active database system. Penggunaan teknologi ini diharapkan proses penyampaian update harga pasar dapat tersampaikan dengan efektif.

\section{Metode Penelitian}

Penelitian ini menggunakan metode penelitian action research merupakan penelitian yang berfokus langsung pada tindakan sosial. Action research adalah penelitian baik kualitatif maupun kuantitatif. Penelitian tindakan adalah cara melakukan masalah pada saat yang bersamaan. Penelitian tindakan ini merupakan metode yang didasarkan pada tindakan masyarakat yang seringkali diselenggarakan pada suatu latar yang luas, seperti di rumah sakit, pabrik, sekolah, dan lain sebagainya [3].

Dalam penelitian ini menggunakan metode pengembangan basis data database life cycle. Tahapantahapan dalam proses perancangan sistem basis data sebenarnya merupakan bagian dalam database life cycle. Pada tahapan ini dilakukan proses menciptakan rancangan untuk basis data yang akan mendukung operasi dan tujuan suatu enterprise.

Penelitian ini menggunakan analisis untuk menentukan kelemahan dan kelebihan suatu sistem informasi pelayanan informasi harga pasar, dan mencari asal dari permasalahan yang terjadi selanjutnya memikirkan alternatif untuk pemecahan masalah serta mencari solusi terbaik untuk pemecahan masalah tersebut [5].

Data pada penelitian ini dikumpulkan sesuai kebutuhan data penelitian. Data-data yang dikumpulkan merupakan database operasional yang terdapat pada sistem informasi yang sudah ada pada website. Data yang digunakan dalam penelitian ini adalah data yang diambil langsung dari sumber asli dari Desa Gadungan Puncu Kab. Kediri.

\section{Hasil \& PeMbahasan}

Database konvensional hanya mempunyai fungsi dasar sebagai jalur data masuk dan keluar dalam sebuah sistem informasi, tanpa memiliki fungsi tambahan untuk berperilaku reaktif dan meresponse terhadap lingkungan luar database. Model database konvensional dapat dilihat pada gambar 1 


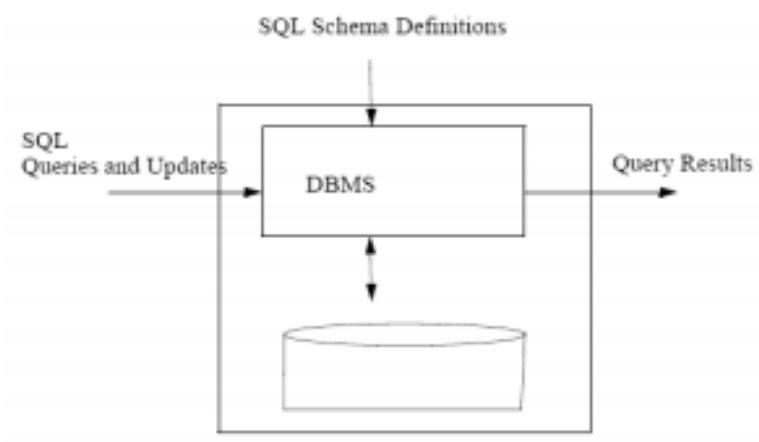

GAMBAR I. MODEL DATABASE KonVENSIONAL

Model active database system menggunakan predefined rule (aturan-aturan yang telah didefinisikan sebelumnya) yang ditanam dalam database[2]. Model ini dapat mengenali perubahan yang terjadi di lingkungan luar database. Model Active Database dapat dilihat pada gambar 2

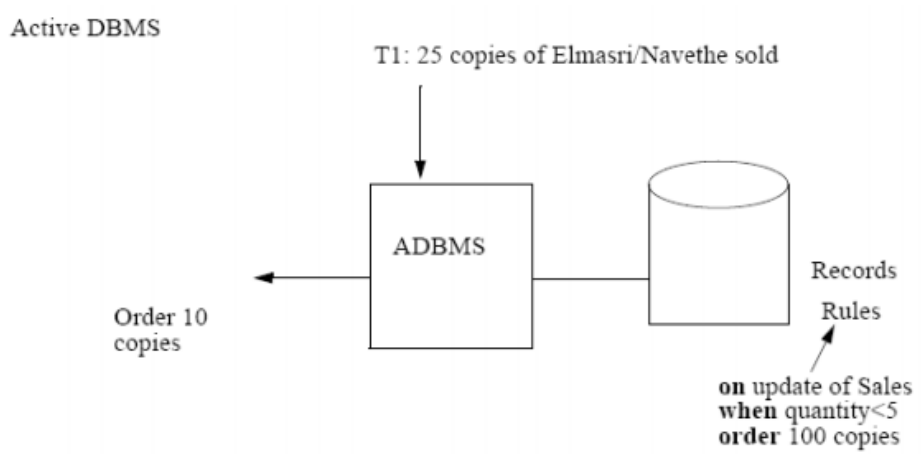

GAMBAR II. MODEL ACTIVE DATABASE

Ketika mengembangkan sebuah sistem informasi dengan landasan aturan bisnis, secara fisik aturanaturan bisnis tersebut disimpan dalam sebuah repository atau tempat penyimpanan data yang dapat dikelola dan diubah setiap saat menggunakan perangkat lunak yang tersedia. Ada 2 solusi yang dapat digunakan dalam mengembangkan sistem informasi [6] yaitu:

\section{Parameter Driven Approach}

Dalam pendekatan ini aturan-aturan disimpan dalam sebuah perangkat lunak database. Aturan-aturan tersebut dikenali dengan sejumlah atribut atau nilai berupa parameter sehingga mampu berkomunikasi dengan aplikasi front-end yang menggunakan aturan. Aplikasi akan mengirimkan nilai-nilai berupa parameter yang telah didefinisikan di dalam aturan yang tersimpan di dalam database. Sehingga melalui parameter-parameter inilah aplikasi dan database saling berkomunikasi untuk bertukar data dan informasi. 
Jurnal INTENSIF, Vol.1, No.1, Februari 2017

ISSN: $2549-6824$

\section{Independent Process Driven Approach}

Dalam pendekatan ini, aturan-aturan mengikuti pola pengembangan sistem informasi tradisional. Aturan diterjemahkan ke dalam kode program di aplikasi secara langsung. Aturan-aturan tersebut tidak disimpan di dalam database, tetapi dalam sebuah lapisan tersendiri, sehingga dapat diakses setiap saat ketika sistem membutuhkan eksekusi aturan tersebut.

Salah satu fitur yang terdapat dalam Active Database System adalah adanya mekanisme pendefinsian Event -Condition - Action (ECA) Rule. Event -Condition - Action (ECA) adalah sebuah cara yang digunakan untuk menangkap perilaku dinamis dalam sebuah sistem informasi. Paradigma ECA telah memberikan dampak yang siginifikan di bidang Sistem Informasi dan telah digunakan dalam Active Database baik secara konseptual maupun dalam implementasinya [ 8].

Paradigma aturan produksi pada Active Database Management System (ADBMS) mengikuti pola aturan produksi pada Arti fficial Intelligence (AI) dengan aturan menyerupai aturan produksi pada sistem pakar [8], yaitu dengan notasi:

$$
\text { Condition } \rightarrow \text { Action (1) }
$$

Suatu mesin kesimpulan beredar mengelilingi aturan di dalam sistem, untuk mempertemukan kondisi bagian dari aturan dengan data dalam memori kerja. Paradigma ini telah membuat sebuah pola di dalam ADBMS terkait ECA-rule dengan pola sebagai berikut:

\section{On event \\ If Condition}

Then Action

Dasar bagi pemicu terjadinya event adalah perintah standar manipulasi data SQL, yaitu perintah INSERT, UPDATE dan DELETE. Perintah standar SQL tersebut membentuk sebuah konsep nilai OLD dan NEW. Nilai NEW diartikan sebagai nilai yang diperoleh dari record akibat perintah INSERT dan DELETE. Dan nilai OLD diartikan sebagai nilai yang telah dihapus akibat perintah DELETE atau nilai sebelum dikenai perintah UPDATE [9].

Dalam implementasinya ECA-rule tidak harus memenuhi seluruh event-condition-Action. Bisa jadi ECA-rule hanya menerapkan Event dan Action (EA) demikian juga hanya menerapkan Condition untuk melakukan Action tertentu (CA). Anatomi dari tipe aturan dapat dilihat pada tabel 1. 
Jurnal INTENSIF, Vol.1, No.1, Februari 2017

ISSN: 2549-6824

TAB EL I. ANATOMI TIPE RULE

\begin{tabular}{ll}
\hline \hline \multicolumn{1}{c}{ Tipe Rule } & \multicolumn{1}{c}{ Anatomi } \\
\hline Derivation Rule & Condition - Action (CA) \\
& Condition Primary Action - Secondary Action (CA | CA2) \\
Action Rule & Action (A) \\
Stimulus/Response & Event - Condition - Action (ECA) \\
& Event - Action (EA) \\
& Event - Condition - Primary Action - Secondary Action \\
& $($ ECA $\mid$ A2) \\
\hline
\end{tabular}

Perancangan Sistem informasi pelayanan harga pasar dibuat sistem informasi berbasis web dan sms. Sistem informasi web digunakan sebagai control data seperti data inbox, outbox, sent dan data-data produk harga pasar. Sistem informasi dapat diakses oleh masyarakat menggunakan media sms tanpa harus melakukan registrasi sebelumnya. Akses informasi dapat dilakukan dengan format yang sudah ditentukan yaitu INFO $<$ spasi $>$ KONTEN. Syntax "INFO" dan "KONTEN" yang diketik bebas yaitu dapat diketik huruf besar maupun kecil atau campuran. Detail siklus sistem layanan pesan singkat dengan proses active database sistem sebagai berikut :

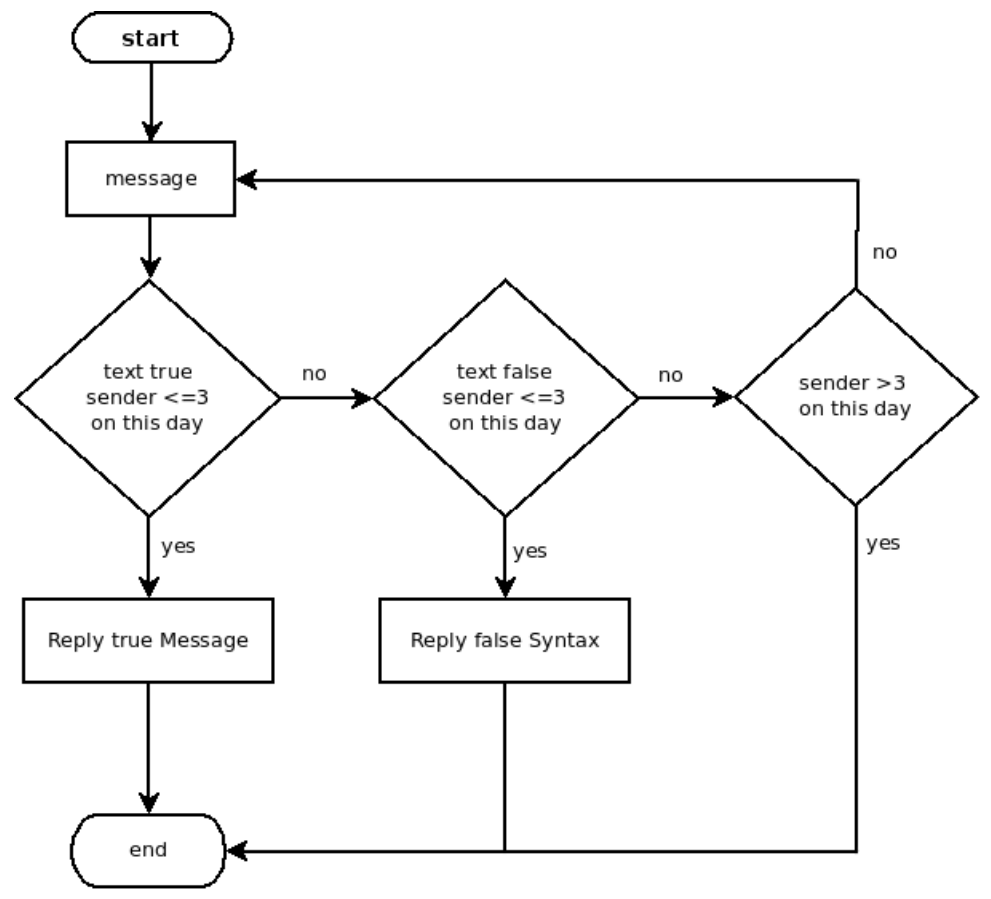

GAMBAR III. FLOWCHART SISTEM

Perancangan basis data pada system dimaksudkan untuk mempermudah hubungan-hubungan antar table satu dengan table yang lainnya. Basis data mempunyai fungsi untuk memverifikasi, mencatat, menyimpan dan menampilkan hasil. Detail tabel yang berisi mengenai entitas dan tipedata dapat dilihat pada tabel 2. 
Jurnal INTENSIF, Vol.1, No.1, Februari 2017

ISSN: $2549-6824$

TABEL II. TABEL PRODUK

\begin{tabular}{ll}
\hline \multicolumn{1}{c}{ Entitas } & \multicolumn{1}{c}{ Tipe data } \\
\hline kode & $\operatorname{int}(5)$ \\
nama & $\operatorname{varchar}(50)$ \\
produk & varchar(50) \\
keterangan & varchar(100) \\
aktif & enum(' $\left.Y^{\prime},{ }^{\prime} \mathrm{N}\right)$ \\
\hline
\end{tabular}

Tabel II merupakan tabel yang berisi produk dan pesan yang akan disampaikan jika syntax konten sesuai dengan nama produk. Tabel II berhubungan dengan tabel III jika pesan yang masuk sesuai dengan kontex menggunakan fungsi pemotongan karakter pesan.

TABEL III. DETAIL TABEL INBOX

\begin{tabular}{ll}
\hline \multicolumn{1}{c}{ Entitas } & \multicolumn{1}{c}{ Tipe data } \\
\hline UpdatedInDB & timestamp \\
ReceivingDate T & timestamp \\
ime & text \\
Text & varchar(20) \\
SenderNumber & enum('Default_No_Compression', \\
Coding & 'Unicode_No_Compres... \\
UDH & text \\
SMSCNumber & varchar(20) \\
Class & int(11) \\
TextDecoded & text \\
ID & int(10) \\
RecipientID & text \\
Processed & enum('false', 'true') \\
id_folder & int(11) \\
readed & enum('false', 'true') \\
\hline
\end{tabular}

Tabel III terdapat dua system active database system. Active database system yang pertama yaitu "inbox_timestamp" merupakan pencatatan waktu otomatis bawaan dari gammu dan yang kedua yaitu "auto_reply" merupakan sistem active database sistem untuk pengelolaan informasi. Ketika sms masuk makan akan otomatis mengirim pesan dan dimasukkan kedalam tabel outbox. Tabel outbox dapat dilihat pada tabel IV. Tabel outbox juga mempunyai fungsi active database yang sama dengan tabel inbox yaitu fungsi timestamp yang dinamakan “outbox_timestamp". 
TABEL IV. DETAIL TABEL OUTBOX

\begin{tabular}{llll}
\hline \multicolumn{1}{c}{ Entitas } & \multicolumn{1}{c}{ Tipe data } & \multicolumn{1}{c}{ Entitas } & \multicolumn{1}{c}{ Tipe data } \\
\hline Update dInDB & timestamp & TextDecoded & text \\
InsertIntoDB & timestamp & ID & int(10) \\
SendingDate Time & timestamp & MultiPart & enum('false', 'true') \\
SendBefore & time & RelativeValidity & int(11) \\
SendAfter & time & SenderID & varchar(255) \\
Text & text & SendingTimeOut & timestamp \\
DestinationNumber & varchar(20) & DeliveryReport & enum('default', 'yes', 'no') \\
Coding & enum('Default_No_Compression' & CreatorID & text \\
UDH &, 'Unicode_No_Compres) & & \\
Class & text & & \\
\hline
\end{tabular}

Proses terakhir ketika pesan terkirim terdapat pada tabel V. Jika pesan terproses maka pesan yang ada pada tabel outbox akan berpindah ke tabel V. Lampiran coding active database system dapat dilihat pada gambar 4.

TABEL V. Det AIl TABEl Sent

\begin{tabular}{|c|c|c|c|}
\hline Entitas & Tipe data & Entitas & Tipe data \\
\hline UpdatedInDB & timestamp & TextDecoded & text \\
\hline Ins ertIntoDB & timestamp & ID & $\operatorname{int}(10)$ \\
\hline SendingDate Time & timestamp & SenderID & $\operatorname{varchar}(255)$ \\
\hline DeliveryDateTime & timestamp & Seque ncePosition & $\operatorname{int}(11)$ \\
\hline Text & text & Status & $\begin{array}{l}\text { enum('SendingOK', } \\
\text { 'SendingOKNoReport', } \\
\text { 'SendingErr... }\end{array}$ \\
\hline DestinationNumber & • $\operatorname{varchar}(20)$ & Status Error & $\operatorname{int}(11)$ \\
\hline Coding & $\begin{array}{l}\text { enum('Default_No_Compress } \\
\text { ion', 'Unicode_No_Compres... }\end{array}$ & TPMR & $\operatorname{int}(11)$ \\
\hline UDH & text & Relative Validity & $\operatorname{int}(11)$ \\
\hline SMSCNumber & $\operatorname{varchar}(20)$ & CreatorID & text \\
\hline Class & $\operatorname{int}(11)$ & id_folder & $\operatorname{int}(11)$ \\
\hline
\end{tabular}

Perancangan script auto reply menggunakan metode active database system sesuai dengan flowchar pada gambar 3. Script ini memungkinkan untuk pelayanan informasi melalui sms gateway. Cara kerja script ini dengan melakukan pembatasan balasan terhadap masyarakat yang ingin mengetahui informasi harga produk-produk pasar di wilayah desa gadungan puncu. 


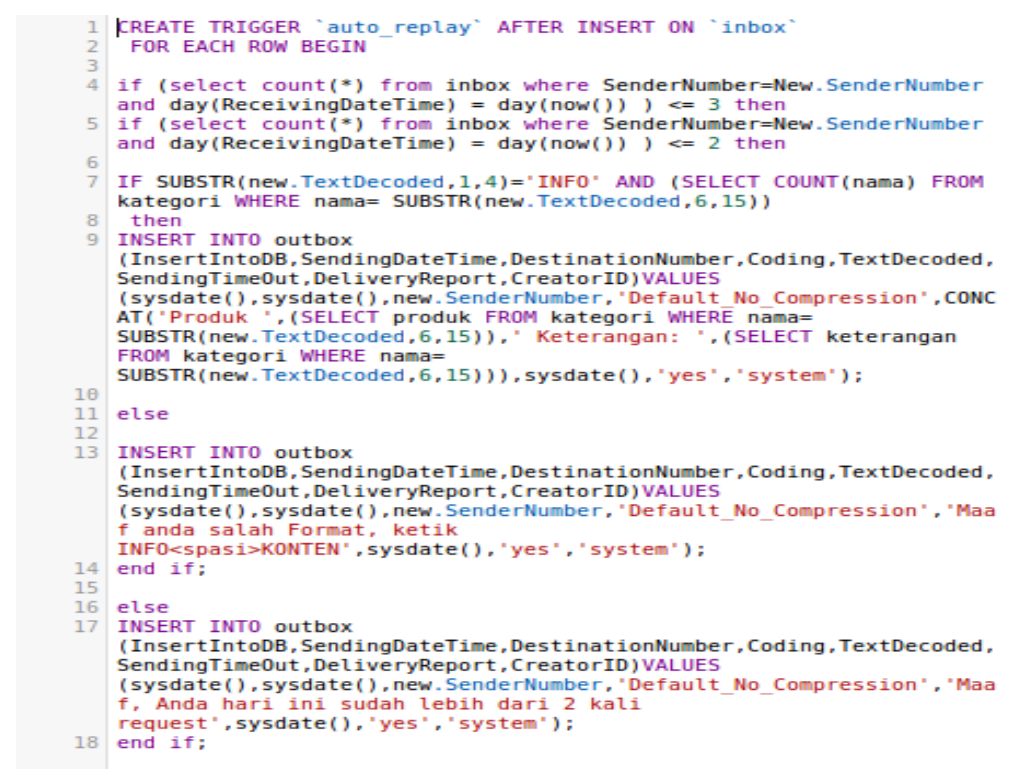

\section{GAMBAR IV. SCRIPT AUto REPLY ACTIVE DATABASE Sistem}

\section{KeSimpulan \& SARAN}

Perancangan sistem yang dibuat diharapkan sesuai engan kebutuhan sistem maupun implementasi ketikan nanti diterapkan ke masyarakat. Sistem yang dibuat masih sebatas desain rancangan database dan penggunaan database. Diharapkan penelitian mendatang dapat mengimplementasikan kedalam aplikasi berbasis web dan mobile.

\section{DAFTAR PUSTAKa}

[1] T.M. Connolly and C.E. Begg, Database systems: a practical approach to design implementation and management (5th edition), America: Pearson Education, 2010

[2] ACT-NET Consortium, The Active Database Management System Manifesto: A Rulebase of ADBMS Features. ACM SIGMOD Record, v.25, n.3, p.40-49, 1996

[3] T.S. Ernest, Action Research, Sage Publications, Inc: USA, 2014.

[4] Indrajani, Perencanaan Basis Data dalam All in 1, Jakarta : elex Media Komputindo, 2011.

[5] Butleris, R; Kapocius, K, The Business Rules Repository For Information Systems Design .ADBIS. Department of Information Systems, Kaunas University of Technology, Lithuania, 2002

[6] Dayal, U, Hanson, E., N, Widom, J, Active Database Systems: Modern Database System: Interoperability, and Beyond. Addison Weley, Reading, Massachusetts, 1994

[7] Elmashri, R., Navathe, B, Fundamentals of Database Systems, Third Edition, Addison Wisley, 2000 